\title{
Anticancer Effects of Emodin on HepG2 Cell: Evidence from Bioinformatic Analysis
}

\author{
Rui-sheng Zhou, ${ }^{1,2}$ Xiong-Wen Wang, ${ }^{1}$ Qin-feng Sun, ${ }^{3}$ Zeng Jie Ye, ${ }^{2}$ Jian-wei Liu, \\ Dai-Han Zhou, ${ }^{1,2}$ and Ying Tang $\oplus^{1,2,5}$ \\ ${ }^{1}$ The First Affiliated Hospital of Guangzhou University of Chinese Medicine, Guangzhou University of Chinese Medicine, \\ Guangzhou, China \\ ${ }^{2}$ Guangzhou University of Chinese Medicine, Guangzhou, China \\ ${ }^{3}$ Stomatological Hospital of Shandong University, Shandong, China \\ ${ }^{4}$ Jinan Stomatological Hospital, Shandong, China \\ ${ }^{5}$ Lingnan Medical Research Center of Guangzhou University of Chinese Medicine, Guangzhou, China
}

Correspondence should be addressed to Ying Tang; 18825144748@163.com

Received 9 January 2019; Revised 31 March 2019; Accepted 23 April 2019; Published 19 May 2019

Academic Editor: Michael Linnebacher

Copyright (c) 2019 Rui-sheng Zhou et al. This is an open access article distributed under the Creative Commons Attribution License, which permits unrestricted use, distribution, and reproduction in any medium, provided the original work is properly cited.

Hepatocellular carcinoma (HCC) is a primary cause of cancer-related death in the world. Despite the fact that there are many methods to treat HCC, the 5-year survival rate of HCC is still at a low level. Emodin can inhibit the growth of HCC cells in vitro and in vivo. However, the gene regulation of emodin in HCC has not been well studied. In our research, RNA sequencing technology was used to identify the differentially expressed genes (DEGs) in HepG2 cells induced by emodin. A total of 859 DEGs were identified, including 712 downregulated genes and 147 upregulated genes in HepG2 cells treated with emodin. We used DAVID for function and pathway enrichment analysis. The protein-protein interaction (PPI) network was constructed using STRING, and Cytoscape was used for module analysis. The enriched functions and pathways of the DEGs include positive regulation of apoptotic process, structural molecule activity and lipopolysaccharide binding, protein digestion and absorption, ECM-receptor interaction, complement and coagulation cascades, and MAPK signaling pathway. 25 hub genes were identified and pathway analysis revealed that these genes were mainly enriched in neuropeptide signaling pathway, inflammatory response, and positive regulation of cytosolic calcium ion concentration. Survival analysis showed that LPAR6, C5, SSTR5, GPR68, and P2RY4 may be involved in the molecular mechanisms of emodin therapy for HCC. A quantitative real-time PCR (qRT-PCR) assay showed that the mRNA levels of LPAR6, C5, SSTR5, GPR68, and P2RY4 were significantly decreased in HepG2 cells treated with emodin. In conclusion, the identified DEGs and hub genes in the present study provide new clues for further researches on the molecular mechanisms of emodin.

\section{Introduction}

Hepatocellular carcinoma (HCC) is a severe disease of the digestive system and is the sixth most common and second leading cause of death due to cancer. While the early stage of HCC can be successfully treated by surgical resection and liver transplantation, most HCC cases are diagnosed only at the late stage, when treatment options are more limited [1-3]. Targeted therapies using sorafenib, regorafenib, and lenvatinib, as well as immunotherapy with a PD-1 inhibitor (nivolumab), have been approved for the treatment of advanced-stage HCC [4-7]. However, there remains an urgent need for the identification and development of novel therapeutic agents and strategies for the treatment of HCC.

Emodin (1,3,8-trihydroxy-6-methylanthraquinone; Figure 1) is an active ingredient derived from Polygonum cuspidatum [8], Rheum palmatum [9], Cassia occidentalis [10], and Polygonum multiflorum [11] and has been used in China for many centuries. The role of emodin as an anticancer drug has been previously described. Modern pharmacological studies have revealed that emodin exhibits various biological activities, such as apoptosis-inducing and antiproliferative 


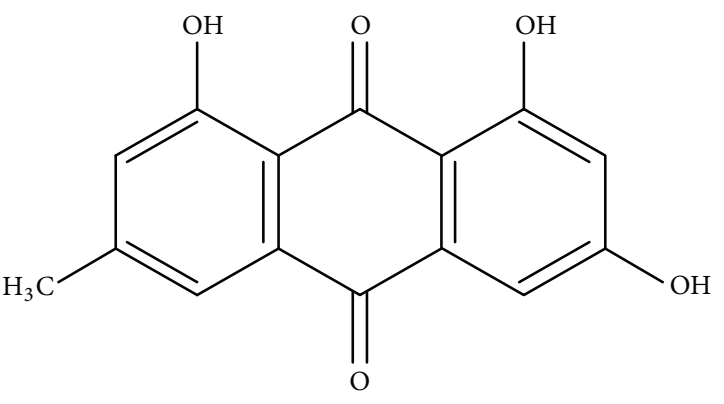

Figure 1: Chemical structure of emodin.

effects in breast cancer [12], pancreatic cancer [13], prostate cancer [14], gastric cancer [15], lung carcinoma [16], colon cancer [17], and HCC [18]. Furthermore, emodin can inhibit metastasis, invasion, and migration in HCC and breast cancer $[19,20]$. Dong et al. showed that emodin induces apoptosis in human HCC [21]. Hsu et al. confirmed that emodin inhibited the growth of hepatoma cells [22]. Numerous studies have confirmed the therapeutic effect of emodin on liver cancer. Thus, it is necessary to identify the key genes associated with emodin in HepG2 cells by conducting comprehensive bioinformatic analysis.

High-throughput technologies, such as transcriptome, protein, metabolite, and RNA sequencing, are high accuracy tools that can be used to identify biomarkers for the treatment, diagnosis, and prognosis of various diseases [23]. RNA sequencing (RNA-seq) uses deep-sequencing technologies to provide precise information regarding transcription profiles. The use of RNA-seq in analyzing the effects of drug treatments presents significant advantages including the identification of differentially expressed genes (DEGs) associated with the drug. Network and functional enrichment analyses are also beneficial in understanding the molecular mechanisms underlying drug action.

Although emodin exhibits good clinical efficacy, its gene regulatory mechanisms in liver cancer cells have not been systematically elucidated. Therefore, it is necessary to measure the expression levels of DEGs in cancer cells after treatment with emodin and to systematically analyze the functions of these genes. To overcome the aforementioned issue, the transcriptomes of emodin-treated HepG2 cells were profiled using RNA-seq method. The DEGs induced by emodin treatment were then examined in more detail using a series of analysis tools. The hub genes were extracted, and their corresponding expression levels were compared. A series of survival analyses was then conducted to determine whether the hub genes are correlated with poor prognosis. The relationship between the hub genes and tumor progression in patients with HCC was analyzed. Finally, statistical analysis of functional DEGs was performed, and their potential possible contributions to the anticancer effects of emodin were discussed.

\section{Materials and Methods}

2.1. Drug. Emodin was purchased from the Chinese Medicine Center in Beijing, dissolved in dimethylsulfoxide (DMSO) at a concentration of $100 \mathrm{mM}$, and stored at $-20^{\circ} \mathrm{C}$.
The compound was diluted in the appropriate medium to $25,50,75$, and $100 \mu \mathrm{M}$ immediately before use. The final concentration of DMSO was $<0.1 \%$.

2.2. Cell Culture. Human hepatocellular carcinoma HepG2 cells were purchased from cell bank of the institute of Biochemistry and Cell Biology, Shanghai Institutes for Biological Sciences, Chinese Academy of Science (http://www.cellbank.org.cn/). Cells were cultured in RPMI1640 medium (GIBCO, Grand Island, NY, USA), with $10 \%$ fetal bovine serum (FBS, Gemini, US), $100 \mathrm{U} / \mathrm{ml}$ penicillin, and $100 \mathrm{mg} / \mathrm{ml}$ streptomycin in a humidified atmosphere with $5 \% \mathrm{CO} 2$ at $37^{\circ} \mathrm{C}$ (Thermo Fisher Science, MA, USA). The cells with $80 \%$ confluence were treated by emodin of different concentrations. In this study, we have pooled 3 biological repeats into one RNA-seq experiment to achieve the same amount of total RNA content. More specifically, at the cell culturing section, cancer cells in 6 different petri dishes were divided into two equal groups. One group was used as emodin treated group, and the other was used as control/untreated group.

2.3. Cell Proliferation Assay. Cell Counting Kit- 8 assay was used to measure cell proliferation. HepG2 cells were seeded in 96-well plates at $5 \times 10^{3}$ cells/well and incubated at $37^{\circ} \mathrm{C}$ in complete medium for $24 \mathrm{~h}$ before being treated with increasing concentrations of emodin for up to $72 \mathrm{~h}$. Then the cells were incubated with $10 \mu \mathrm{l} \mathrm{CCK} 8$ at $37^{\circ} \mathrm{C}$ for $2 \mathrm{~h}$. Absorbance at $450 \mathrm{~nm}$ was determined using a microplate reader as recommended by the manufacturer. All experiments were performed in triplicate and repeated at least three times with essentially similar results. The inhibition rate was calculated as follows: inhibition rate $(\%)=$ [average OD value (control)average OD value (medication)]/average OD value (control) $\times 100 \%$. The IC50 value was calculated on the nonlinear regression fit method by the GraphPad Prism software.

2.4. RNA-Seq and Analysis. We have pooled 3 biological repeats into one RNA-seq experiment to achieve the same amount of total RNA content. More specifically, at the cell culturing section, cancer cells in 6 different petri dishes were divided into two equal groups. One group was used as emodin treated group, and the other was used as control/untreated group. Briefly, after being treated with emodin for $72 \mathrm{~h}$, total RNA was extracted using Trizol reagent (Invitrogen, Carlsbad, CA, USA). We use Agilent 2100 Bio analyzer (Agilent RNA 6000 Nano Kit) to do the total RNA sample QC: RNA concentration, RIN value, $28 \mathrm{~S} / 18 \mathrm{~S}$, and the fragment length distribution. We filter the low quality reads (more than $20 \%$ of the bases qualities are lower than 10), reads with adaptors, and reads with unknown bases ( $\mathrm{N}$ bases more than $5 \%$ ) to get the clean reads. Then we assembled those clean reads into Unigenes, followed with Unigene functional annotation, SSR detection and calculate the Unigene expression levels and SNPs of each sample. Finally, we identify DEGs (differential expressed genes) between samples and do clustering analysis and functional annotations. We use internal software SOAPnuke to filter reads, as follows: (1) remove reads with adaptors; (2) remove reads in which unknown bases $(\mathrm{N})$ are more 
than $10 \%$; (3) remove low quality reads (we define the low quality read as the percentage of base whose quality is lesser than 15 and is greater than $50 \%$ in a read). After filtering, the remaining reads are called "Clean Reads" and stored in FASTQ format. We use HISAT (Hierarchical Indexing for Spliced Alignment of Transcripts) to do the mapping step because HISAT is much faster and sensitive and is a high accuracy analysis software [24]. We mapped clean reads to reference using Bowtie2 [25], and then calculated gene expression level with RSEM [26]. RSEM is a software package for estimating gene and isoform expression levels from RNASeq data. Then, we calculate Pearson correlation between all samples using cor, perform hierarchical clustering between all samples using hclust, perform PCA analysis with all samples using princomp, and draw the diagrams with ggplot2 with fuctions of R. We detect DEGs with DEGseq [27]. DEGs at each stage or site were used for further analyses of GO (gene ontology) Molecular Function and KEGG pathways using by the Database for Annotation, Visualization, and Integrated Discovery (DAVID: http://david.abcc.ncifcrf.gov).

2.5. PPI Network Construction and Module Analysis. The PPI network was predicted using Search Tool for the Retrieval of Interacting Genes (STRING; http://string-db.org) [28] online database. Analyzing the functional interactions between proteins may provide insights into the mechanisms of generation or development of diseases. In the present study, PPI network of DEGs was constructed using STRING database, and an interaction with a combined score $>0.7$ was considered statistically significant. Cytoscape is an open source bioinformatics software platform for visualizing molecular interaction networks [29]. The plug-in ClusterONE (version 1.0) of Cytoscape is an APP for clustering a given network based on protein-protein interaction networks [30]. The PPI networks were drawn using Cytoscape and the most significant module in the PPI networks was identified using ClusterONE. Subsequently, the KEGG and GO analyses for genes in this module were performed using DAVID.

2.6. Hub Genes Selection and Analysis. The hub genes were selected with degrees $\geq 10$ [31]. A network of the genes and their coexpression genes was analyzed using cBioPortal (http://www.cbioportal.org) online platform [4, 14]. The overall survival and disease-free survival analyses of hub genes were performed using Kaplan-Meier curve in cBioPortal [32].

2.7. Quantitative Real-Time PCR. A quantitative real-time PCR (qRT-PCR) assay was developed for the detection and quantification of AXIN2, WNT5B, WNT3A, CATENIN, and GSK3B transcripts using ACTIN as an endogenous control. The primers used in this study were designed as follows: ACTIN forward $5^{\prime}$-CACCCAGCACAATGAAGATCAAGAT- ${ }^{\prime}$; reverse $5^{\prime}$-CCAGTTTTTAAATCCTGAGTCAAGC-3'. P2RY4 forward 5'-CTGGACTGTTGGTTTGATGAGGA- $3^{\prime}$; reverse $5^{\prime}$-CAGCGACAGCACATACAAGGT-3'; C5 forward $5^{\prime}$-GGAGTGACGGTGCTGGAGTTT-3'; reverse $5^{\prime}$-CCCTCGTGCCAAAGTGGATAA-3'; SSTR5 forward5' - CTACATTCTCAACCTGGCAGTGG-3'; reverse $5^{\prime}$-GCTCATGACTGTCAGGCAGAAGA-3'. LPAR6 forward $5^{\prime}$-GGTAAGCGTTAACAGCTCCCAC-3'; reverse $5^{\prime}$ - CATTTCGGACTTTGAGGACGC-3'. GPR68 forward $5^{\prime}$-CAACTCCTCGATGAGCTGTACCA-3'; reverse $5^{\prime}$ AGGTAGCCGAAGTAGAGGGACA-3' . qRT-PCR was performed in a $20 \mu \mathrm{L}$ mixture containing $2 \mu \mathrm{L}$ of the cDNA preparation, $10 \mu \mathrm{L} 2 x$ SYBR Green Premix ExTaq (Takara), and $10 \mu \mathrm{M}$ primer on an ABI 7500 Real-Time PCR System (Applied Biosystems, Grand Island, NY, USA). The PCR conditions were as follows: $10 \mathrm{~min}$ at $95^{\circ} \mathrm{C}$, followed by 40 cycles of $15 \mathrm{~s}$ at $95^{\circ} \mathrm{C}$, and $1 \mathrm{~min}$ at $60^{\circ} \mathrm{C}$. Each sample was tested in triplicate. Threshold values were determined for each sample/primer pair, and the average and standard errors were calculated.

\section{Results}

3.1. Emodin Inhibits HepG2 Cell Growth in the Time- and Dose-Dependent Manner. We analyzed the effect of emodin on HepG2 cell proliferation. CCK8 assays were performed using the HCC cell line, HepG2, after treatment with different concentrations of emodin for 24,48 , and $72 \mathrm{~h}$. As shown in Figure 2, emodin decreased cell viability in a dose- and timedependent manner, and the 50\% inhibitory concentration $\left(\mathrm{IC}_{50}\right.$ ) observed at $72 \mathrm{~h}$ was $19.12 \mu \mathrm{M}$ in HepG2 cells.

3.2. RNA-Seq Landscape. Treatment of HepG2 cells via emodin dose-response assays revealed that emodin had $\mathrm{IC}_{50}$ values of about $20 \mu \mathrm{M}$ at $72 \mathrm{~h}$. The whole transcriptomic profiles of HepG2 cells and of those treated with emodin were assessed at base-pair resolution via RNA sequencing. After removing the low-quality reads, the raw reads from each sample were mapped to a reference genome (Table 1).

3.3. Identification of DEGs. DEGs were screened and generated by comparing the emodin samples to the control samples. As shown in the column diagram (Figure 3(a)) and volcano plot (Figure 3(b)), the analysis identified 859 DEGs comprising 712 downregulated genes and 147 upregulated genes that satisfy the criteria $\log 2$ (fold change) $>3$ and adj. p-value $<0.001$.

3.4. KEGG and GO Enrichment Analyses of DEGs. To determine the biological classifications of the DEGs, functional and pathway enrichment analyses were performed using DAVID, and the GO functional enrichments of the upregulated and downregulated genes were determined at a p-value of less than 0.05. GO analysis results showed that changes in biological processes (BP) of DEGs were significantly enriched in cellular heat acclimation, positive regulation of apoptotic process, response to lipopolysaccharide, negative regulation of inclusion body assembly, negative regulation of extrinsic apoptotic signaling pathway in absence of ligand, negative regulation of endopeptidase activity, extracellular matrix organization, homophilic cell adhesion via plasma membrane adhesion molecules, wound healing, and fibrinolysis (Table 2). Changes in cell component (CC) of DEGs were mainly enriched in extracellular space, extracellular region, proteinaceous extracellular matrix, integral component of 
TAble 1: General Statistics of Reads Alignment Process.

\begin{tabular}{lccc}
\hline Sample & Total Raw Reads $(\mathrm{M})$ & Total Clean Reads $(\mathrm{M})$ & Total Mapping $(\%)$ \\
\hline Emodin1 & 21.81 & 21.65 & 92.18 \\
Emodin2 & 21.81 & 21.61 & 92.31 \\
Emodin3 & 21.84 & 21.68 & 92.28 \\
Control1 & 21.94 & 21.86 & 94.59 \\
Control2 & 21.94 & 21.86 & 94.66 \\
Control3 & 21.94 & 21.87 & 94.59 \\
\hline
\end{tabular}

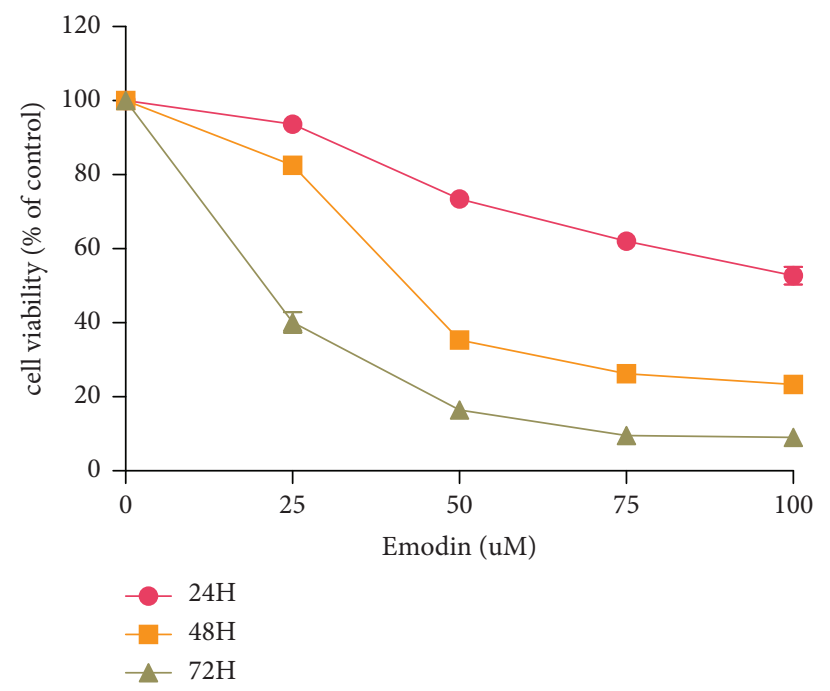

FIGURE 2: Emodin inhibits HepG2 cell growth in the time- and dose-dependent manner. HepG2 cells were treated with increased concentrations of emodin for up to $72 \mathrm{hrs}$ to examine the cell viability. The cell viability was determined using the CCK8 assay as described in Materials and Methods and was expressed as percentage of control in the mean \pm SD of three separate experiments.

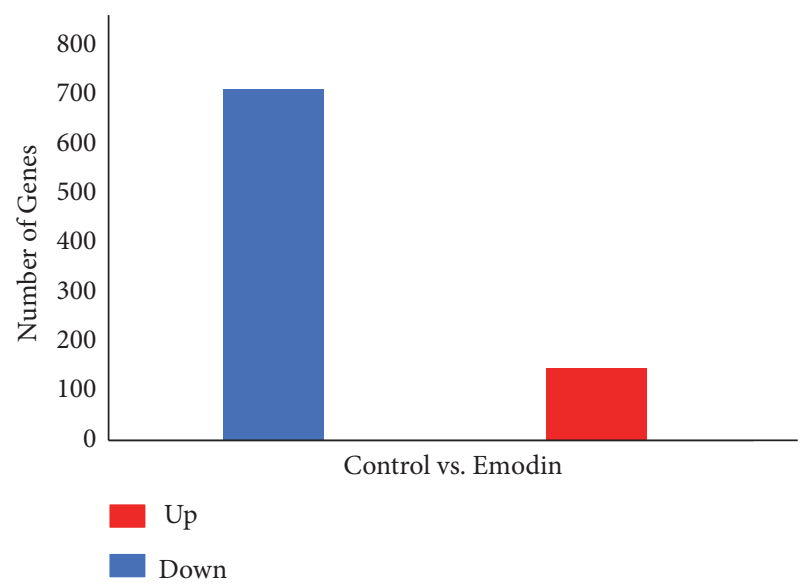

(a)

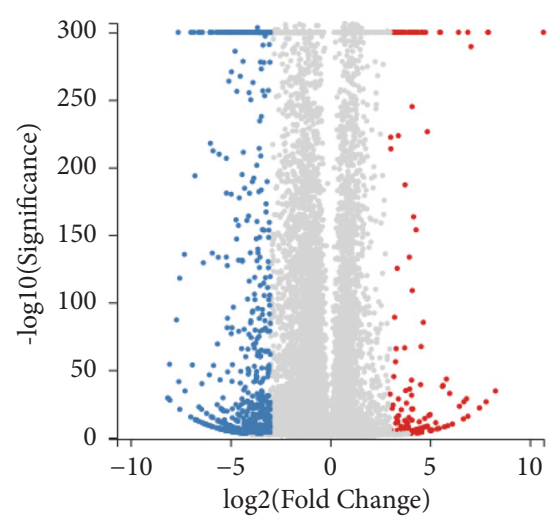

Up no-DEGS

Down

(b)

FIGURE 3: Column diagram and Volcano Plot of DEGs. DEGs were selected with a log 2 (fold change) $>3$ and adj. P-value $<0.001$ among the mRNA expression of emodin and control. (a) Column diagram of DEGs. (b) Volcano Plot of DEGs. Upregulated genes are marked in light red; downregulated genes are marked in light blue. 
membrane, integral component of plasma membrane, and myofibril (Table 2). Changes in molecular function (MF) were mainly enriched in ATPase activity, coupled, serinetype endopeptidase activity, serine-type peptidase activity, bradykinin receptor activity, protein domain specific binding, calcium ion binding, serine-type endopeptidase inhibitor activity, extracellular matrix structural constituent, structural molecule activity, and lipopolysaccharide binding (Table 2). KEGG pathway analysis revealed that the DEGs were mainly enriched in complement and coagulation cascades, amoebiasis, ECM-receptor interaction, protein digestion and absorption, platelet activation, MAPK signaling pathway, rheumatoid arthritis, estrogen signaling pathway, legionellosis, and metabolism of xenobiotics by cytochrome P450 (Table 2).

3.5. PPI Network Construction and Module Analysis. To analyze the functional contributions of the DEGs, protein-protein interaction (PPI) network analysis was performed using STRING and Cytoscape. The false discovery rate (FDR) for each p-value was calculated. In general, the terms with FDR values $<0.01$ were considered significantly enriched. The PPI network and the most significant module of the DEGs were determined (Figures 4(a) and 4(b)). Functional and pathway enrichment analyses of the genes involved in the module were performed using DAVID. Results showed that the genes in the most significant module were predominantly enriched for terms associated with inflammatory response, neuropeptide signaling pathway, and positive regulation of cytosolic calcium ion concentration (Table 3 ).

3.6. Hub Gene Analysis. A total of 25 genes were identified as hub genes with degree $\geq 10$. The 25 most significant genes showing significant interaction were OPRD1, AVP, BDKRB2, TAS2R4, KNG1, BDKRB1, AGT, PTGDR2, LPAR6, C5, OPRL1, ADRA2C, CCL16, OXER1, CORT, SSTR5, PYY, MCHR1, UTS2R, ANXA1, ADCY1, GPR68, PIK3R1, P2RY4, and HCAR2. The functional roles of these hub genes are shown in Table 4. Coexpression of these hub genes was determined using cBioPortal (Figure 5). To further analyze these hub genes, overall survival and disease-free survival analyses were performed using a Kaplan-Meier curve. HCC patients with C5 and LPAR6 alterations showed low overall survival (Figure 6(a)), and HCC patients with SSTR5, P2RY4, LPAR6, and GPR68 alterations showed low disease-free survival (Figure 6(b)). Results based on qRT-PCR revealed that the mRNA levels of LPAR6, C5, SSTR5, GPR68, and P2RY4 were significantly downregulated in HepG2 cells (Figure 7). These findings indicated that C5, SSTR5, P2RY4, LPAR6, and GPR68 play important roles in the molecular mechanisms involved in emodin therapy for HCC.

\section{Discussion}

Transcription is an important biological process that determines the proteome of the cells. In this study, the RNA profile of HepG2 cells was determined via RNA-seq to explore the functions of DEGs in cancer cells treated with emodin. A total of 859 DEGs were screened, including 712 downregulated genes and 147 upregulated genes in HepG2 cells treated with emodin. These DEGs were found to be associated with emodin-mediated inhibition of liver cancer proliferation. Functional and pathway enrichment analyses of the 859 DEGs were performed using DAVID. GO analysis results showed that the DEGs were mainly enriched in regulation of apoptotic process and extracellular matrix organization. KEGG pathway analysis revealed that the DEGs were mainly enriched in mitogen-activated protein kinase (MAPK) signaling pathway. MAPK is a family of protein kinases comprising the p38 MAPKs, the c-jun $\mathrm{N}$-terminal kinases (JNKs), and the extracellular regulated kinases (ERKs) [36]. MAPKs play crucial roles in regulating various cellular processes, such as cell proliferation. Our findings indicated that emodinmediated inhibition of HCC cell proliferation is associated with the MAPK signaling pathway. The DEGs induced by emodin treatment were then carefully identified using a suite of sequence analysis software packages. Weighted gene coexpression network analysis has been successfully used to identify coexpression modules and intramodular hub genes based on DEG expression data. Analyzing the functional interactions between proteins can provide insights into the mechanisms underlying the effects of emodin in HCC. PPI networks were generated using Cytoscape and the most significant module in the PPI networks was identified using ClusterONE. The hub genes of the most significant module were then selected based on the cutoff degree $\geq 10$. A total of 25 genes were identified as hub genes: OPRD1, AVP, BDKRB2, TAS2R4, KNG1, BDKRB1, AGT, PTGDR2, LPAR6, C5, OPRL1, ADRA2C, CCL16, OXER1, CORT, SSTR5, PYY, MCHR1, UTS2R, ANXA1, ADCY1, GPR68, PIK3R1, P2RY4, and HCAR2. The functional and pathway enrichment analyses of the 25 hub genes were performed using DAVID. GO analysis results showed that changes in $\mathrm{BP}$ of hub genes were significantly enriched in positive regulation of cytosolic calcium ion concentration, G-protein coupled receptor signaling pathway, adenylate cyclase-inhibiting G-protein coupled receptor signaling pathway, neuropeptide signaling pathway, and inflammatory response. Changes in CC of hub genes were mainly enriched in integral component of plasma membrane and plasma membrane. Changes in MF were mainly enriched in neuropeptide binding and G-protein coupled receptor activity. KEGG pathway analysis revealed that the hub genes were mainly enriched in neuroactive ligand-receptor interaction. To further analyze these hub genes, overall survival and disease-free survival analyses were performed using a Kaplan-Meier curve. Results showed that $\mathrm{C} 5$ and LPAR6 are associated with the overall survival of HCC patients. SSTR5, P2RY4, LPAR6, and GPR68 are related to the disease-free survival of HCC patients. These five genes are closely related to prognosis of HCC patients. Verification of the results by qRT-PCR showed that emodin can downregulate the mRNA levels of LPAR6, C5, SSTR5, GPR68, and P2RY4 in HepG2 cells (Figure 7). Therefore, C5, SSTR5, P2RY4, LPAR6, and GPR68 are likely to play important roles in the molecular mechanisms involved in emodin therapy for HCC. In summary, the five hub genes can reflect the molecular mechanisms of emodin therapy for HCC and could serve as targets for emodin therapy for HCC. 


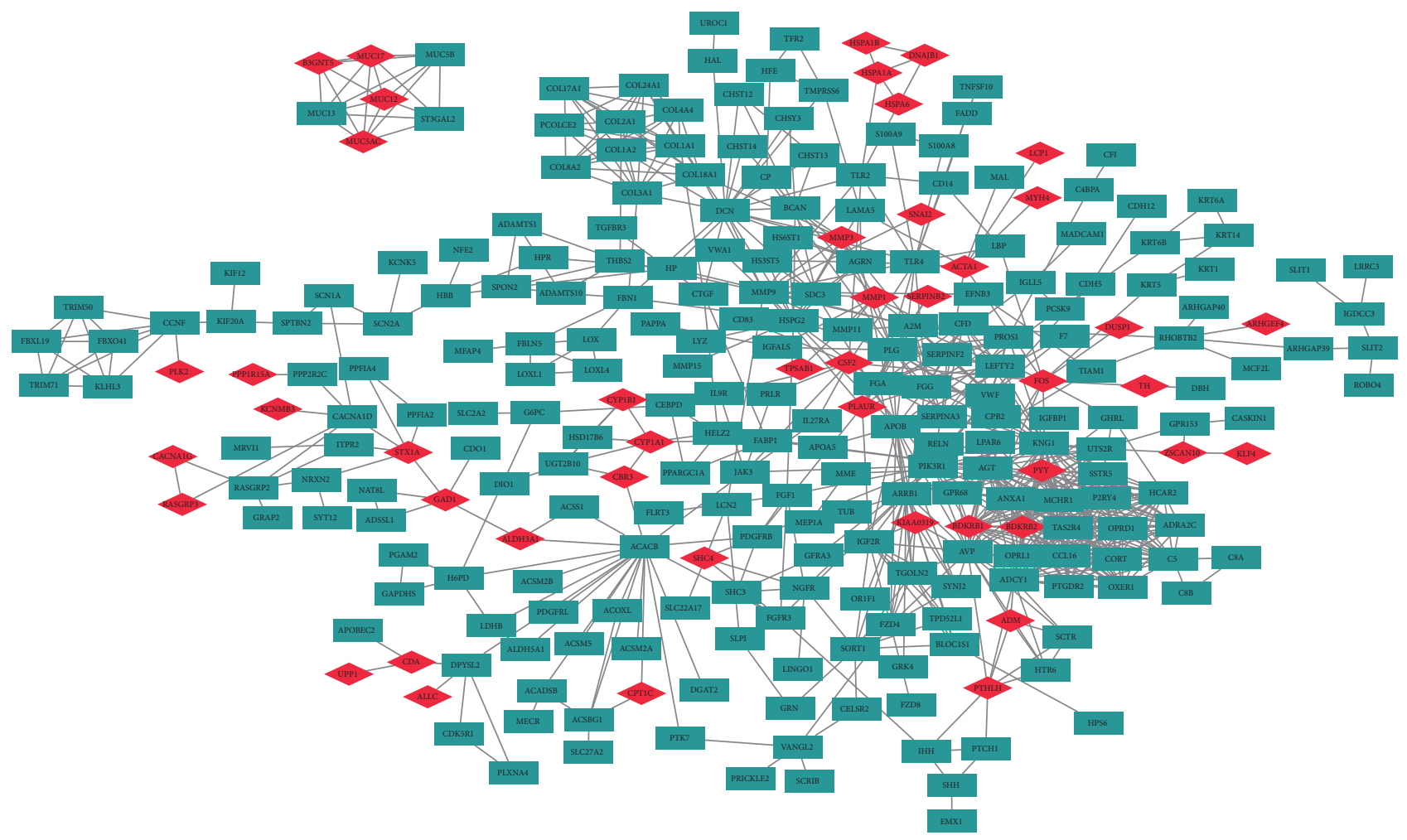

(a)

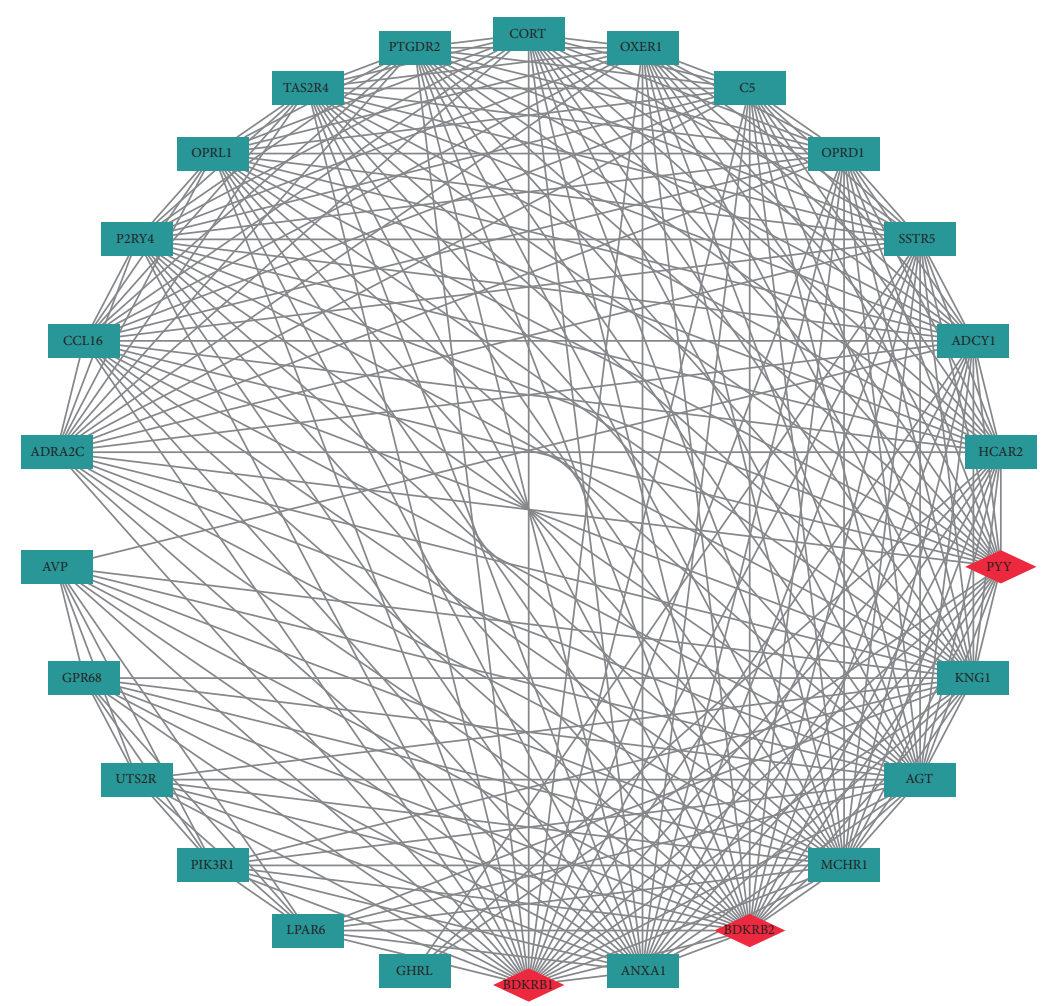

(b)

Figure 4: PPI network and the most significant module of DEGs. (a) The PPI network of DEGs was constructed using Cytoscape. (b) The most significant module was obtained from PPI network with 26 nodes and 234 edges. Upregulated genes are marked in light red; downregulated genes are marked in light blue. 
TABLE 2: GO and KEGG pathway enrichment analysis of DEGs in HepG2 cells treated with emodin. (Top 5) $\mathrm{P}<0.05$ was considered statistically significant.

\begin{tabular}{|c|c|c|c|}
\hline Category & Term & Count & P-Value \\
\hline \multicolumn{4}{|l|}{ Upregulated } \\
\hline \multirow[t]{5}{*}{ GOTERM_BP } & GO:0070370 cellular heat acclimation & 3 & 3.01E-04 \\
\hline & GO:0043065 positive regulation of apoptotic process & 10 & 3.04E-04 \\
\hline & GO:0032496 response to lipopolysaccharide & 7 & 0.0011565 \\
\hline & GO:0090084 negative regulation of inclusion body assembly & 3 & 0.0021952 \\
\hline & GO:2001240 negative regulation of extrinsic apoptotic signaling pathway in absence of ligand & 4 & 0.0023164 \\
\hline \multirow[t]{3}{*}{ GOTERM_CC } & GO:0005576 extracellular region & 23 & 0.0032977 \\
\hline & GO:0030016 myofibril & 3 & 0.0179025 \\
\hline & GO:0005615 extracellular space & 18 & 0.0200543 \\
\hline \multirow[t]{5}{*}{ GOTERM_MF } & GO:0042623 ATPase activity, coupled & 3 & 0.0031569 \\
\hline & GO:0004252 serine-type endopeptidase activity & 7 & 0.0097873 \\
\hline & GO:0008236 serine-type peptidase activity & 4 & 0.0102052 \\
\hline & GO:0004947 bradykinin receptor activity & 2 & 0.0141671 \\
\hline & GO:0019904 protein domain specific binding & 6 & 0.0164848 \\
\hline \multirow[t]{5}{*}{ KEGG_PATHWAY } & hsa04010:MAPK signaling pathway & 10 & $2.68 \mathrm{E}-04$ \\
\hline & hsa05323:Rheumatoid arthritis & 5 & 0.0066631 \\
\hline & hsa04915:Estrogen signaling pathway & 5 & 0.0100336 \\
\hline & hsa05134:Legionellosis & 4 & 0.010905 \\
\hline & hsa00980:Metabolism of xenobiotics by cytochrome $\mathrm{P} 450$ & 4 & 0.0252724 \\
\hline \multicolumn{4}{|l|}{ Downregulated } \\
\hline \multirow[t]{5}{*}{ GOTERM_BP } & GO:0010951 negative regulation of endopeptidase activity & 23 & $3.10 \mathrm{E}-10$ \\
\hline & GO:0030198 extracellular matrix organization & 25 & $1.58 \mathrm{E}-07$ \\
\hline & GO:0007156 homophilic cell adhesion via plasma membrane adhesion molecules & 21 & $9.99 \mathrm{E}-07$ \\
\hline & GO:0042060 wound healing & 14 & $5.01 \mathrm{E}-06$ \\
\hline & GO:0042730 fibrinolysis & 8 & $5.57 \mathrm{E}-06$ \\
\hline \multirow[t]{5}{*}{ GOTERM_CC } & GO:0005615 extracellular space & 114 & 8.37E-18 \\
\hline & GO:0005576 extracellular region & 124 & $5.51 \mathrm{E}-16$ \\
\hline & GO:0005578 proteinaceous extracellular matrix & 35 & $1.88 \mathrm{E}-10$ \\
\hline & GO:0016021 integral component of membrane & 261 & $2.10 \mathrm{E}-10$ \\
\hline & GO:0005887 integral component of plasma membrane & 96 & $2.35 \mathrm{E}-09$ \\
\hline \multirow[t]{5}{*}{ GOTERM_MF } & GO:0005509 calcium ion binding & 63 & $8.97 \mathrm{E}-11$ \\
\hline & GO:0004867 serine-type endopeptidase inhibitor activity & 20 & $1.22 \mathrm{E}-09$ \\
\hline & GO:0005201 extracellular matrix structural constituent & 12 & 2.27E-05 \\
\hline & GO:0005198 structural molecule activity & 23 & $7.88 \mathrm{E}-05$ \\
\hline & GO:0001530 lipopolysaccharide binding & 7 & $9.18 \mathrm{E}-05$ \\
\hline \multirow[t]{5}{*}{ KEGG_PATHWAY } & hsa04610:Complement and coagulation cascades & 18 & $2.02 \mathrm{E}-10$ \\
\hline & hsa05146:Amoebiasis & 16 & $5.35 \mathrm{E}-06$ \\
\hline & hsa04512:ECM-receptor interaction & 13 & $6.15 \mathrm{E}-05$ \\
\hline & hsa04974:Protein digestion and absorption & 13 & $6.90 \mathrm{E}-05$ \\
\hline & hsa04611:Platelet activation & 14 & 8.04E-04 \\
\hline
\end{tabular}




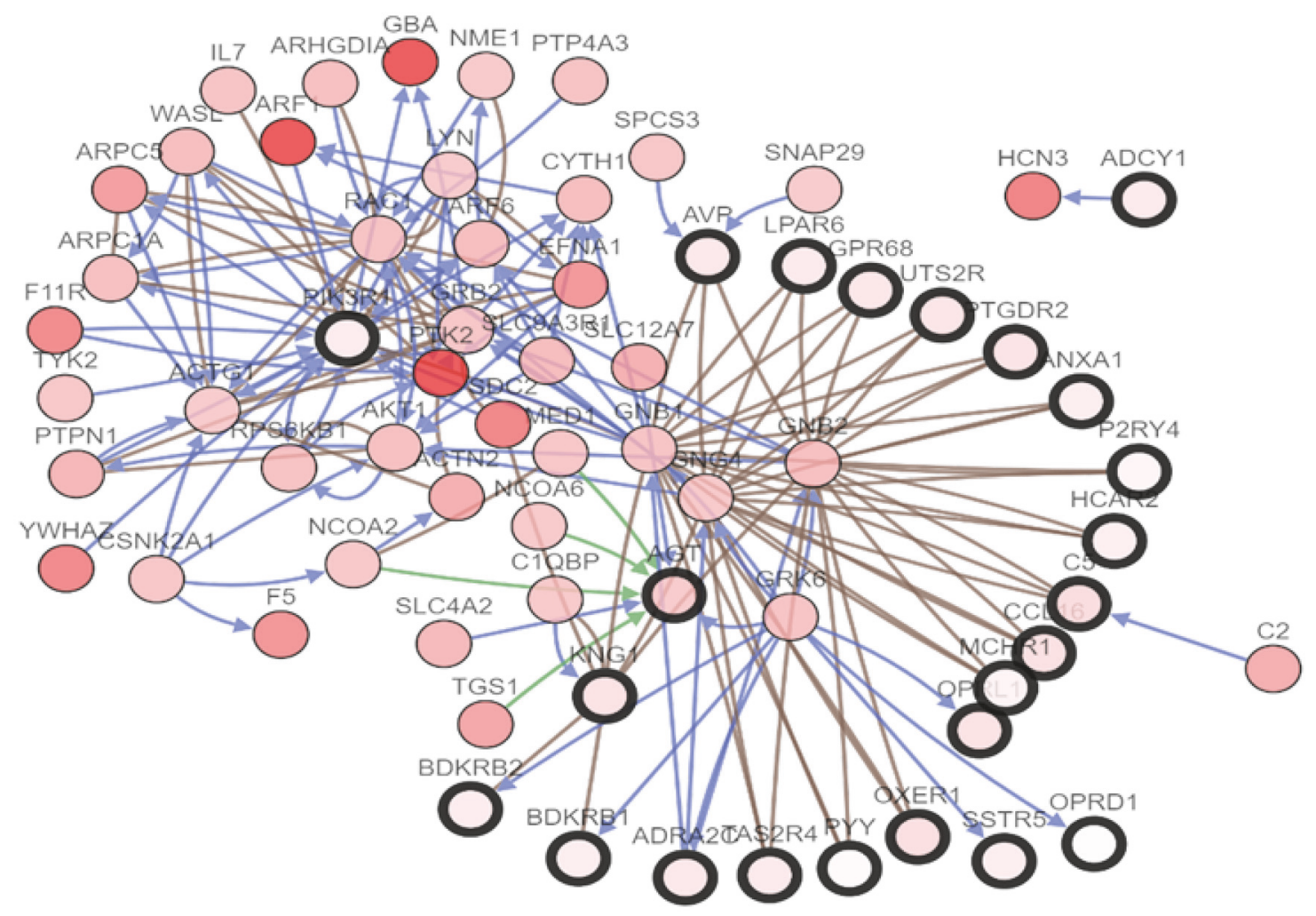

FIGURE 5: Interaction network analysis of the hub genes. Hub genes and their coexpression genes were analyzed using cBioPortal. Nodes with bold black outline represent hub genes. Nodes with thin black outline represent the coexpression genes.

TABLE 3: GO and KEGG pathway enrichment analysis of DEGs in the module. FDR $<0.05$ was considered statistically significant.

\begin{tabular}{|c|c|c|c|}
\hline Category & Term & Count & FDR \\
\hline \multirow[t]{5}{*}{ GOTERM_BP } & GO:0007204 positive regulation of cytosolic calcium ion concentration & 10 & $2.54 \mathrm{E}-10$ \\
\hline & GO:0007186 G-protein coupled receptor signaling pathway & 15 & $5.11 \mathrm{E}-09$ \\
\hline & GO:0007193 adenylate cyclase-inhibiting G-protein coupled receptor signaling pathway & 6 & $9.72 \mathrm{E}-06$ \\
\hline & GO:0007218 neuropeptide signaling pathway & 6 & $4.76 \mathrm{E}-04$ \\
\hline & GO:0006954 inflammatory response & 7 & 0.0216325 \\
\hline \multirow[t]{2}{*}{ GOTERM_CC } & GO:0005887 integral component of plasma membrane & 13 & 9.27E-05 \\
\hline & GO:0005886 plasma membrane & 19 & $2.11 \mathrm{E}-04$ \\
\hline \multirow[t]{2}{*}{ GOTERM_MF } & GO:0042923 neuropeptide binding & 4 & 0.0035638 \\
\hline & GO:0004930 G-protein coupled receptor activity & 8 & 0.0619499 \\
\hline KEGG_PATHWAY & hsa04080:Neuroactive ligand-receptor interaction & 10 & $1.78 \mathrm{E}-05$ \\
\hline
\end{tabular}

GO, gene ontology; KEGG, Kyoto Encyclopedia of Genes and Genomes; DEGs, differentially expressed genes; FDR, false discovery rate

Complement activation is regulated to provide a permanent source of complement mediators that can maintain the inflammatory microenvironment that favors tumor growth $[13,37]$. Complement component 5 (C5) is the fifth component of the complement and can be cleaved into C5a and C5b by C5-convertase. It plays a critical role in cell killing and inflammatory processes [38]. Many studies have reported that a variety of tumor cell lines can produce the complement activation product C5a. Furthermore, it has been reported that plasma C5a levels are elevated in liver cancer and other tissue-specific cancers $[1,6,15]$. He et al. showed that C5 levels were upregulated in AFP(-) HBV-related HCC and that C5 is potentially strongly associated with the progression of AFP() HBV-related HCC [17]. In addition, tumor inflammatory microenvironments were found to contain the complementactivating components $\mathrm{C} 3, \mathrm{C} 4, \mathrm{C} 5, \mathrm{Clq}$, and $\mathrm{MAC}$ in many cancer models [39]. Somatostatin receptor type 5 (SSTR5) is a receptor that can lead to somatostatin-mediated inhibition of the release of hormones and secretory proteins [40]. A previous study reported that SSTR5 levels are upregulated in 

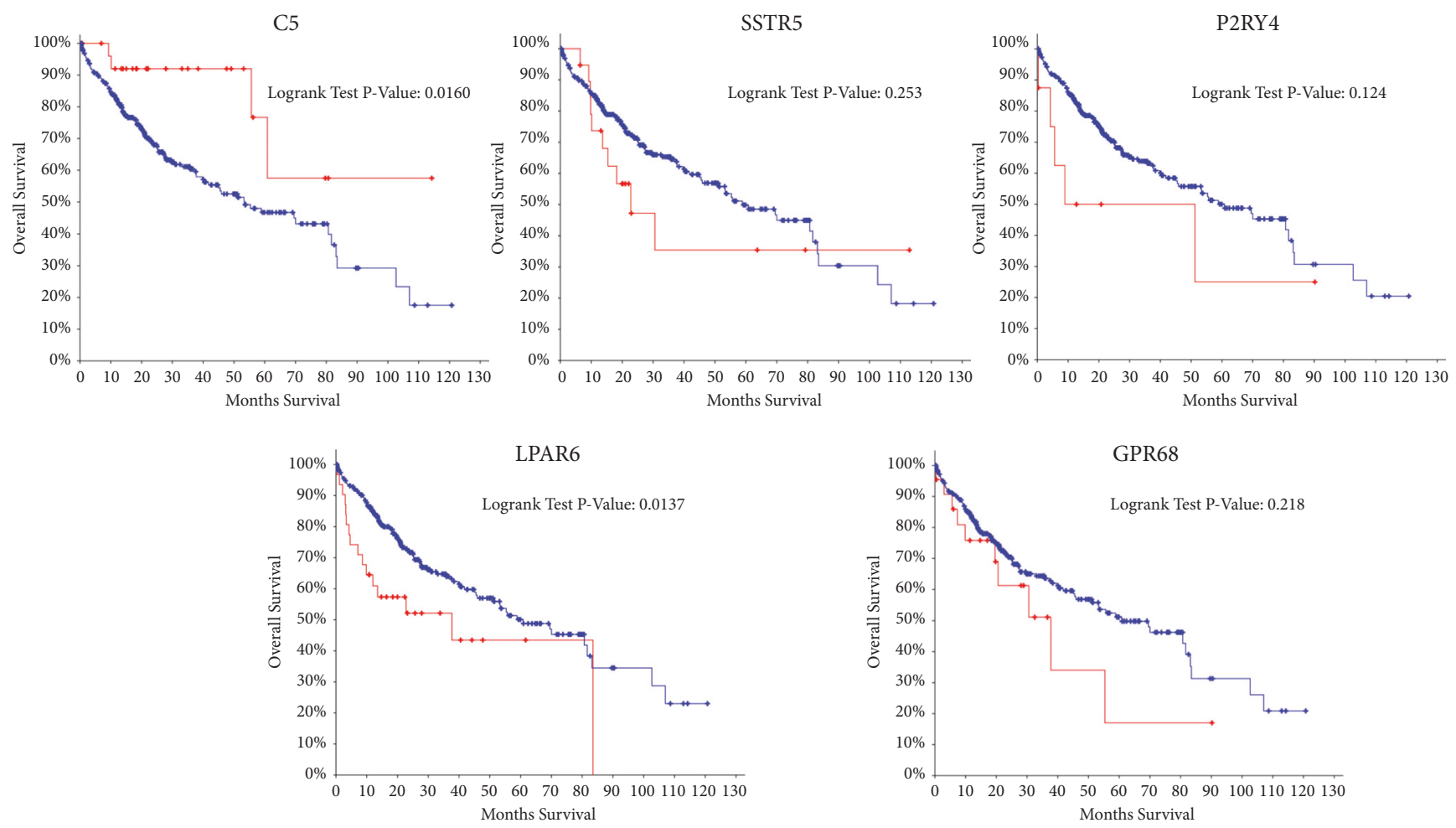

$\square$ Cases with Alteration(s) in Query Gene(s)

Cases without Alteration(s) in Query Gene(s)

(a)

C5

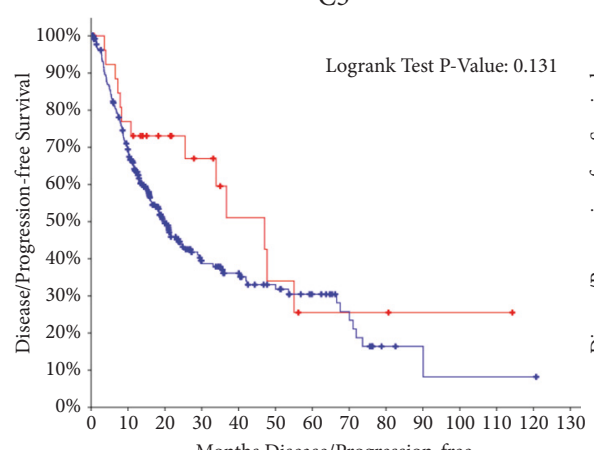

Months Disease/Progression-free

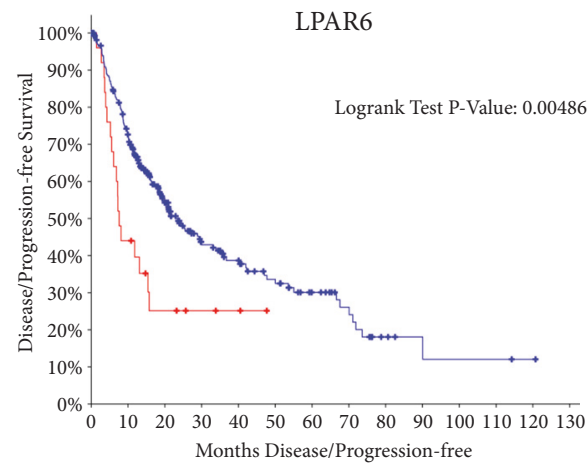

SSTR5
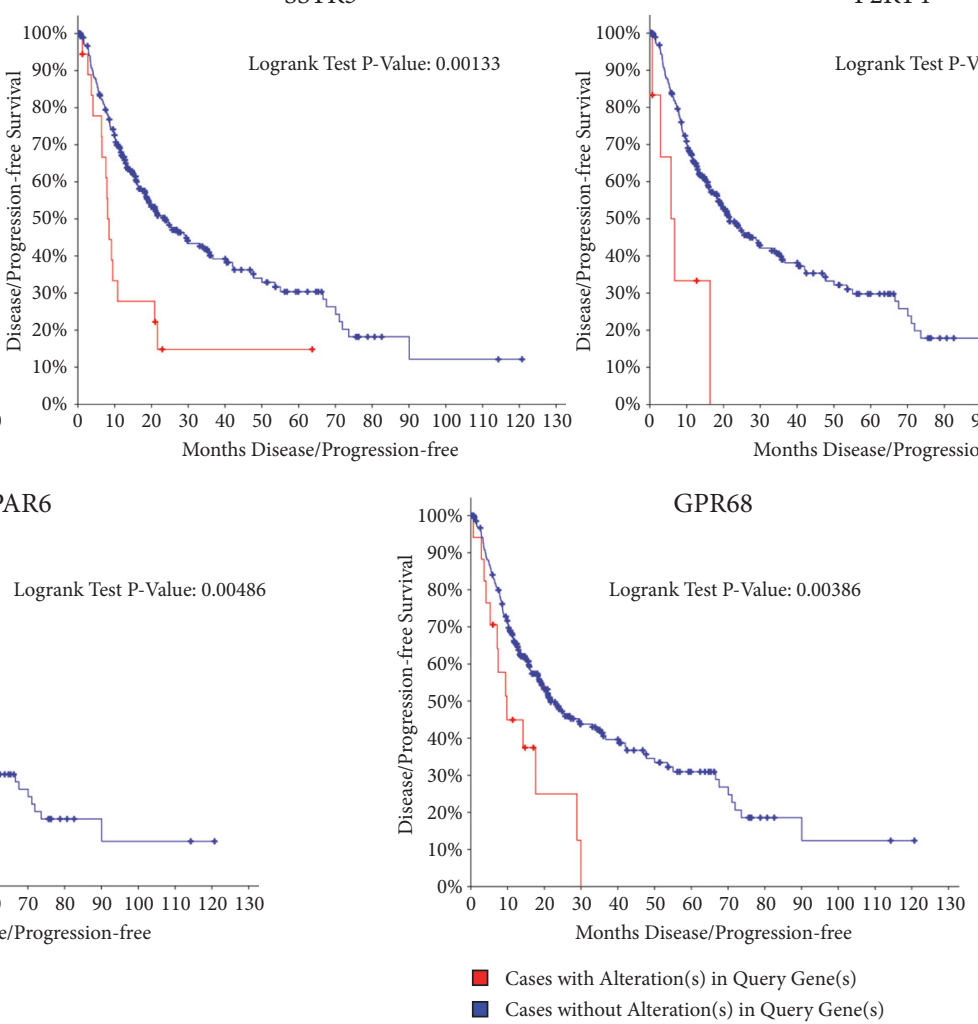

(b)

Figure 6: (a) Overall survival and (b) disease-free survival analyses of hub genes were performed using cBioPortal online platform. $\mathrm{P}<0.05$ was considered statistically significant. 


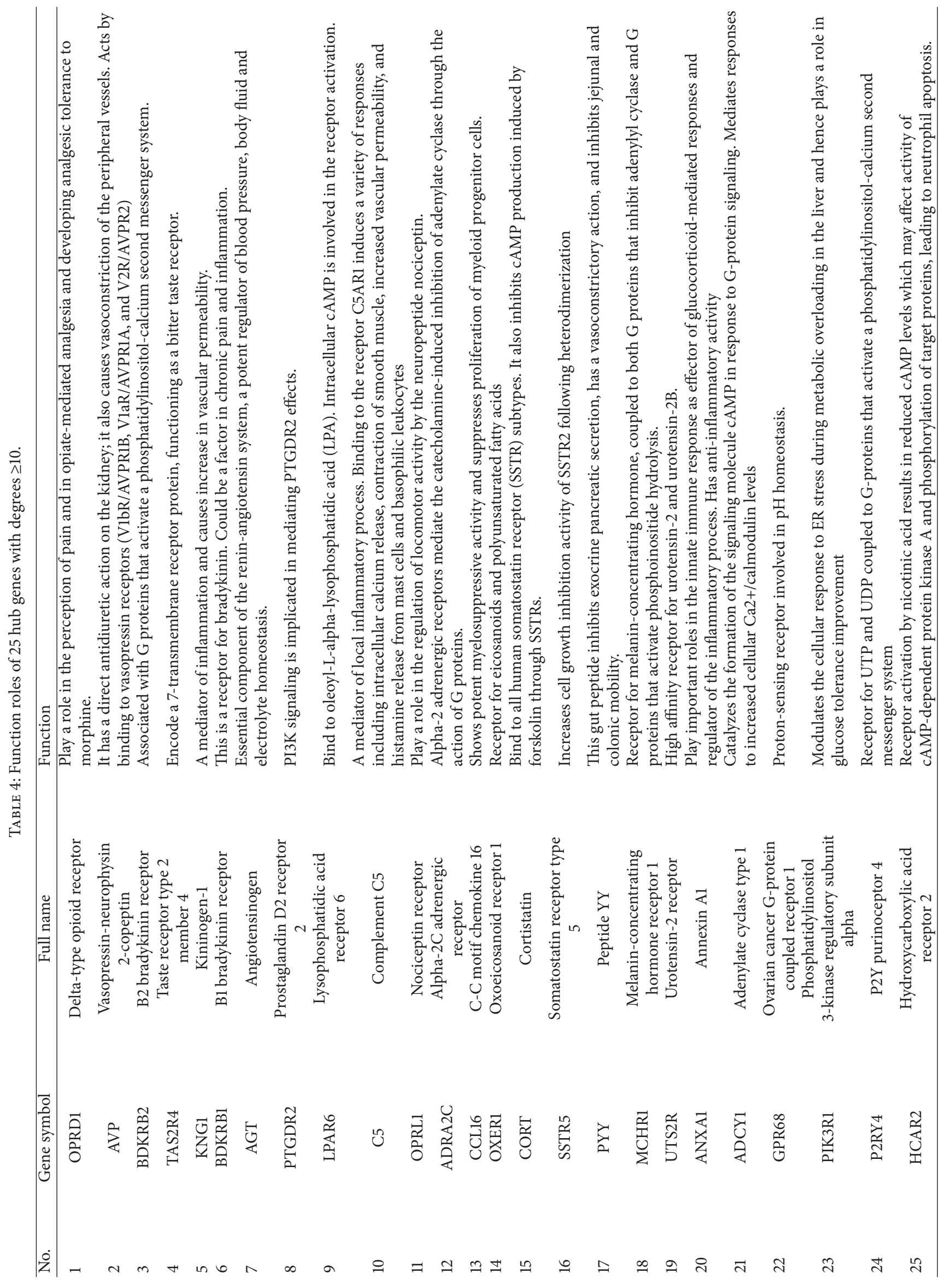



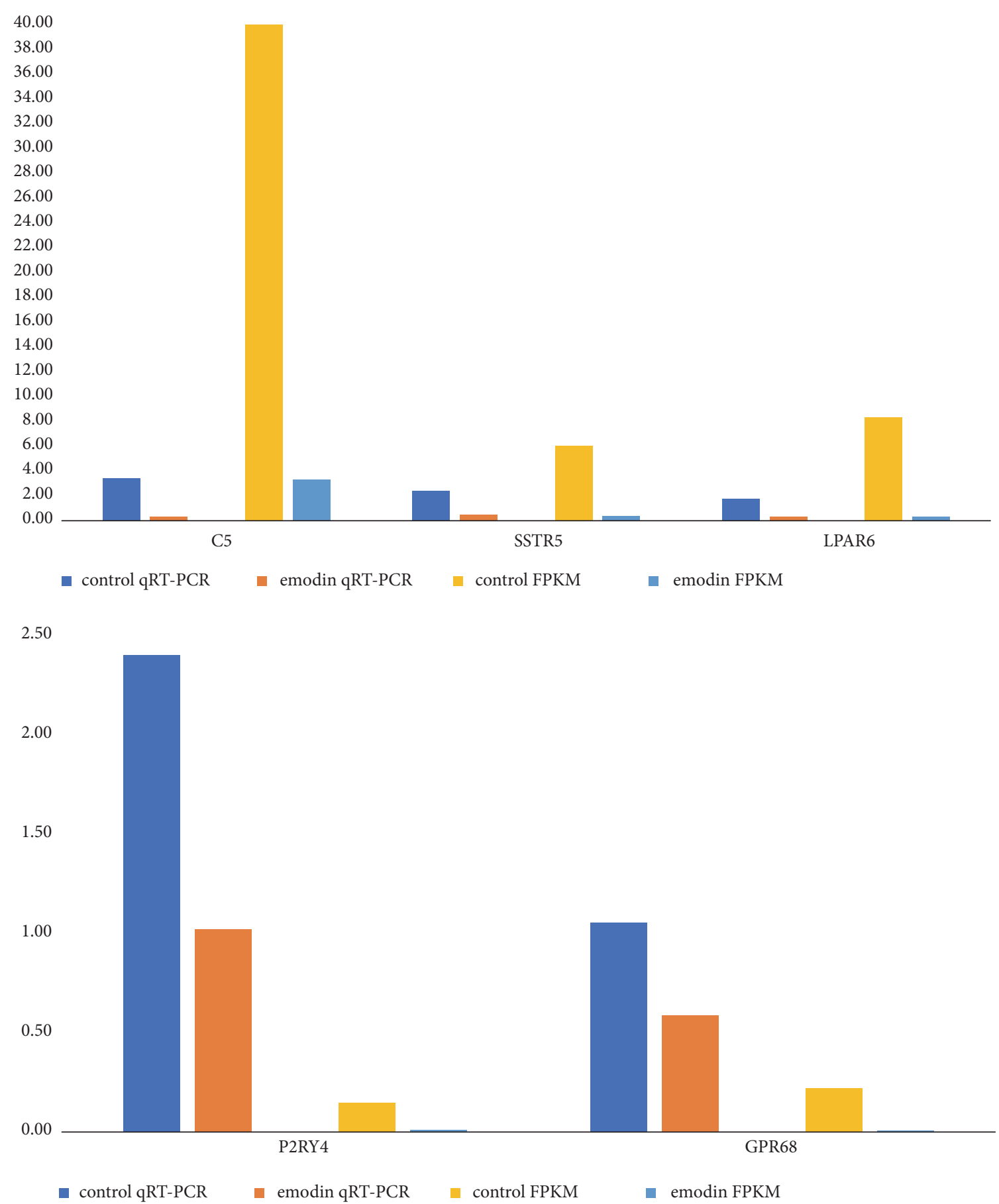

FIGURE 7: qRT-PCR validation of 5 differentially expressed hub DEGs. Comparison of fold change of LPAR6, C5, SSTR5, GPR68, and P2RY4 between RNA seq and qRT-PCR results.

advanced-stage HCC [23]. SSTR5 can bind to somatostatin analogues, such as octreotide, which can help determine the antiproliferative efficacy of somatostatin analogues [2]. In addition, a positive correlation has been reported between SSTR5 expression and tumor size [8]. Lysophosphatidic acid receptor 6 (LPAR6) is a G protein-coupled receptor that can bind to lysophosphatidic acid [41]. One study reported that LPAR6 is essential for maintaining the tumorigenic properties of HCC cells; patient data and the experimental evidence supported the claim that LPAR6 promotes tumorigenicity and growth in HCC by activating the protooncogene Pim-3 [33]. Emodin can downregulate the expression of C5, SSTR5, and LPAR6. So far, no studies have examined the expression levels of P2Y purinoceptor 4 (P2RY4) and G-protein coupled receptor 68 (GPR68) in HCC. P2RY4, a G-protein coupled receptor, is responsive to uridine nucleotides [18] and plays an important role in transporting chloride in the epithelium of the jejunum [10]. The role of P2RY4 in apoptosis and cell 
TABLE 5: Function roles of 5 genes in cancer.

\begin{tabular}{|c|c|c|c|}
\hline Gene & Expression in cancer & Function in cancer & Ref \\
\hline $\mathrm{C} 5$ & Upregulated in HCC & Highly associated with the progression of AFP(-) HBV-related HCC. & [17] \\
\hline SSTR5 & Upregulated in HCC & $\begin{array}{l}\text { Regulate intracellular signaling pathways, such as MAPK pathways; constitute a } \\
\text { molecular basis for the treatment of HCC with somatostatin analogues. }\end{array}$ & {$[2,32]$} \\
\hline LPAR6 & Upregulated in HCC & $\begin{array}{l}\text { Maintain the proliferation capacity and the tumorigenic phenotype of HCC } \\
\text { through the transcriptional activation of protooncogene Pim- } 3 \text {. }\end{array}$ & [33] \\
\hline P2RY4 & $\begin{array}{l}\text { Upregulated in colonic } \\
\text { cancer }\end{array}$ & $\begin{array}{l}\text { The function is based on the effect of extracellular nucleotides on apoptosis or cell } \\
\text { proliferation in HCT8 and Caco- } 2 \text { cells. }\end{array}$ & [7] \\
\hline GPR68 & $\begin{array}{l}\text { Upregulated in PDAC and } \\
\text { ovarian cancer }\end{array}$ & $\begin{array}{l}\text { Stimulates PDAC proliferation; } \\
\text { inhibits ovarian cancer cell proliferation and migration, but enhances the cell } \\
\text { adhesion to the extracellular matrix }\end{array}$ & {$[34,35]$} \\
\hline
\end{tabular}

proliferation, based on the effect of extracellular nucleotides, has been studied in HCT8 and Caco 2 cells [7]. In ovarian cancer, GPR68 is coupled to the PLC/Ca2+ pathway via the Gq/11 protein [42]. GPR68 is nearly undetectable in the healthy pancreas but is highly expressed in pancreatic ductal adenocarcinoma (PDAC) [34]. In human ovarian cancer cells, GPR68 has been shown to promote adhesion of cells to the extracellular matrix [35]. Among the five hub genes, C5, SSTR5, and LPAR6 were found to be involved in HCC (Table 5). These three genes could serve as the targets of emodin therapy for HCC (Table 5). However, few studies have investigated the relationships among P2RY4, GPR68, and liver cancer, and elucidating these relationships could be a direction for future research.

\section{Conclusion}

The present study attempted to identify DEGs that may be involved in the molecular mechanisms of emodin therapy for HCC. A total of 859 DEGs and 5 hub genes were identified and may be regarded as targets of emodin therapy for HCC. However, further studies are needed to elucidate the molecular mechanisms and biological function of these genes involved in emodin therapy for HCC.

$\begin{array}{ll}\text { Abbreviations } \\ \text { HCC: } & \text { Hepatocellular carcinoma } \\ \text { RNA-seq: } & \text { RNA sequencing } \\ \text { DEGs: } & \text { Differentially expressed genes } \\ \text { BP: } & \text { Biological processes } \\ \text { CC: } & \text { Cell component } \\ \text { MF: } & \text { Molecular function } \\ \text { GO: } & \text { Gene ontology } \\ \text { KEGG: } & \text { Kyoto Encyclopedia of Genes and } \\ & \text { Genomes } \\ \text { DMSO: } & \text { Dimethylsulfoxide } \\ \text { qRT-PCR: } & \text { Quantitative real-time PCR } \\ \text { IC50: } & \text { Inhibitory concentrations of 50\% } \\ \text { MAPK: } & \text { Mitogen-activated protein kinase } \\ \text { JNKs: } & \text { c-jun N-terminal kinases } \\ \text { ERKs: } & \text { Extracellular regulated kinases }\end{array}$

C5: $\quad$ Component 5

SSTR5: Somatostatin receptor type 5

LPAR6: Lysophosphatidic acid receptor 6

P2RY4: P2Y purinoceptor 4

GPR68: Ovarian cancer G-protein coupled receptor 1

PDAC: Pancreatic ductal adenocarcinoma.

\section{Data Availability}

The data used to support the findings of this study are included within the article.

\section{Conflicts of Interest}

The authors declare that they have no conflicts of interest.

\section{Authors' Contributions}

Rui-sheng Zhou, Qin-feng Sun, and Zeng Jie Ye conducted experiments, collected the data, and wrote the manuscript. Jian-wei Liu and Dai-Han Zhou conducted experiments. Ying Tang collected data, contributed to the discussion, and reviewed the manuscript. Xiong-Wen Wang revised the manuscript. Ying Tang is the guarantor of this work and, as such, has full access to all the data in the study and takes responsibility for the integrity of the data and the accuracy of the data analysis. Rui-sheng Zhou and Xiong-Wen Wang contributed equally to this work.

\section{Acknowledgments}

This work was supported by High-level University Construction of Guangzhou University of Chinese Medicine (A1AFD018181A29 and A1-2606-18-414-016).

\section{References}

[1] L. Bjørge, J. Hakulinen, O. K. Vintermyr et al., "Ascitic complement system in ovarian cancer," British Journal of Cancer, vol. 92, no. 5, pp. 895-905, 2005.

[2] M. Bläker, M. Schmitz, A. Gocht et al., "Differential expression of somatostatin receptor subtypes in hepatocellular carcinomas," Journal of Hepatology, vol. 41, no. 1, pp. 112-118, 2004. 
[3] J. Bruix, S. Qin, P. Merle et al., "Regorafenib for patients with hepatocellular carcinoma who progressed on sorafenib treatment (RESORCE): a randomised, double-blind, placebocontrolled, phase 3 trial," The Lancet, vol. 389, no. 10064, pp. 56-66, 2017.

[4] E. Cerami, J. Gao, U. Dogrusoz et al., "The cBio Cancer Genomics Portal: an open platform for exploring multidimensional cancer genomics data," Cancer Discovery, vol. 2, no. 5, pp. 401-404, 2012.

[5] T. Cha, L. Qiu, C. Chen, Y. Wen, and M. Hung, "Emodin downregulates androgen receptor and inhibits prostate cancer cell growth," Cancer Research, vol. 65, no. 6, pp. 2287-2295, 2005.

[6] L. Corrales, D. Ajona, S. Rafail et al., "Anaphylatoxin C5a creates a favorable microenvironment for lung cancer progression," The Journal of Immunology, vol. 189, no. 9, pp. 4674-4683, 2012.

[7] R. Coutinho-Silva, L. Stahl, K.-K. Cheung et al., "P2X and P2Y purinergic receptors on human intestinal epithelial carcinoma cells: Effects of extracellular nucleotides on apoptosis and cell proliferation," American Journal of Physiology-Gastrointestinal and Liver Physiology, vol. 288, no. 5, pp. G1024-G1035, 2005.

[8] S. V. De Sá, M. L. Corrêa-Giannella, M. C. Machado et al., "Somatostatin receptor subtype 5 (SSTR5) mRNA expression is related to histopathological features of cell proliferation in insulinomas," Endocrine-Related Cancer, vol. 13, no. 1, pp. 6978, 2006.

[9] X. Dong, B. Ni, J. Fu et al., "Emodin induces apoptosis in human hepatocellular carcinoma HepaRG cells via the mitochondrial caspasedependent pathway," Oncology Reports, vol. 40, no. 4, pp. 1985-1993, 2018.

[10] G. R. Dubyak, "Knock-out mice reveal tissue-specific roles of P2Y receptor subtypes in different epithelia," Molecular Pharmacology, vol. 63, no. 4, pp. 773-776, 2003.

[11] A. B. El-Khoueiry, B. Sangro, T. Yau et al., "Nivolumab in patients with advanced hepatocellular carcinoma (CheckMate 040): an open-label, non-comparative, phase 1/2 dose escalation and expansion trial," The Lancet, vol. 389, no. 10088, pp. 24922502, 2017.

[12] A. Franceschini, D. Szklarczyk, S. Frankild et al., "STRING v9.1: protein-protein interaction networks, with increased coverage and integration," Nucleic Acids Research, vol. 41, no. 1, pp. D808D815, 2013.

[13] D. Gancz and Z. Fishelson, "Cancer resistance to complementdependent cytotoxicity (CDC): problem-oriented research and development," Molecular Immunology, vol. 46, no. 14, pp. 27942800, 2009.

[14] J. Gao, B. A. Aksoy, U. Dogrusoz, and ETAL, "Integrative analysis of complex cancer genomics and clinical profiles using the cBioPortal," Science Signaling, vol. 6, p. 11, 2013.

[15] J. Gminski, J. Mykala-Ciesla, M. Machalski et al., "Immunoglobulins and complement components levels in patients with lung cancer," Romanian Journal of Internal Medicine, vol. 30, pp. 3944, 1992.

[16] Y. A. Goo and D. R. Goodlett, "Advances in proteomic prostate cancer biomarker discovery," Journal of Proteomics, vol. 73, no. 10, pp. 1839-1850, 2010.

[17] X. He, Y. Wang, W. Zhang et al., "Screening differential expression of serum proteins in AFP-negative HBV-related hepatocellular carcinoma using iTRAQ -MALDI-MS/MS," Neoplasma, vol. 61, no. 1, pp. 17-26, 2014.

[18] M. Horckmans, E. Léon-Gómez, B. Robaye et al., "Gene deletion of P2Y4 receptor lowers exercise capacity and reduces myocardial hypertrophy with swimming exercise," American Journal of Physiology-Heart and Circulatory Physiology, vol. 303, no. 7, pp. 835-843, 2012.

[19] C.-M. Hsu, Y.-A. Hsu, Y. Tsai et al., "Emodin inhibits the growth of hepatoma cells: finding the common anti-cancer pathway using Huh7, Hep3B, and HepG2 cells," Biochemical and Biophysical Research Communications, vol. 392, no. 4, pp. 473478, 2010.

[20] P. H. Huang, C. Y. Huang, M. C. Chen et al., "Emodin and aloeemodin suppress breast cancer cell proliferation through ER alpha inhibition," Evidence-Based Complementary and Alternative Medicine, vol. 2013, Article ID 376123, 12 pages, 2013.

[21] K. Ikeda, M. Kudo, S. Kawazoe et al., "Phase 2 study of lenvatinib in patients with advanced hepatocellular carcinoma," Journal of Gastroenterology, vol. 52, no. 4, pp. 512-519, 2017.

[22] X. Jia, F. Yu, J. Wang et al., "Emodin suppresses pulmonary metastasis of breast cancer accompanied with decreased macrophage recruitment and M2 polarization in the lungs," Breast Cancer Research and Treatment, vol. 148, no. 2, pp. 291302, 2014.

[23] E. U. Koc, T. Ozgur, O. Yerci et al., "Somatostatin receptor 1 (SSTR1) and somatostatin receptor 5 (SSTR5) expression in hepatocellular carcinoma," Hepato-Gastroenterology, vol. 60, no. 127, pp. 1693-1697, 2013.

[24] D. Kim, B. Langmead, and S. L. Salzberg, "HISAT: a fast spliced aligner with low memory requirements," Nature Methods, vol. 12, no. 4, pp. 357-360, 2015.

[25] B. Langmead and S. L. Salzberg, "Fast gapped-read alignment with Bowtie 2," Nature Methods, vol. 9, no. 4, pp. 357-359, 2012.

[26] B. Li and C. N. Dewey, "RSEM: accurate transcript quantification from RNA-Seq data with or without a reference genome," BMC Bioinformatics, vol. 12, p. 323, 2011.

[27] L. Wang, Z. Feng, X. Wang, and X. Zhang, "DEGseq: an $\mathrm{R}$ package for identifying differentially expressed genes from RNA-seq data," Bioinformatics, vol. 26, no. 1, pp. 136-138, 2010.

[28] D. Szklarczyk, A. L. Gable, D. Lyon et al., "STRING v11: protein-protein association networks with increased coverage, supporting functional discovery in genome-wide experimental datasets," Nucleic Acids Research, vol. 47, no. D1, pp. D607-D613, 2019.

[29] M. E. Smoot, K. Ono, J. Ruscheinski, P. L. Wang, and T. Ideker, "Cytoscape 2.8: new features for data integration and network visualization," Bioinformatics, vol. 27, no. 3, pp. 431-432, 2011.

[30] T. Nepusz, H. Yu, and A. Paccanaro, "Detecting overlapping protein complexes in protein-protein interaction networks," Nature Methods, vol. 9, no. 5, pp. 471-472, 2012.

[31] L. Li, Q. Lei, S. Zhang, L. Kong, and B. Qin, "Screening and identification of key biomarkers in hepatocellular carcinoma: evidence from bioinformatic analysis," Oncology Reports, vol. 38, no. 5, pp. 2607-2618, 2017.

[32] E. Wurmbach, Y.-B. Chen, G. Khitrov et al., "Genome-wide molecular profiles of HCV-induced dysplasia and hepatocellular carcinoma," Hepatology, vol. 45, no. 4, pp. 938-947, 2007.

[33] A. Mazzocca, F. Dituri, F. De Santis et al., "Lysophosphatidic acid receptor LPAR6 supports the tumorigenicity of hepatocellular carcinoma," Cancer Research, vol. 75, no. 3, pp. 532-543, 2015.

[34] S. Z. Wiley, K. Sriram, W. Liang et al., "GPR68, a proton-sensing GPCR, mediates interaction of cancer-associated fibroblasts and cancer cells," The FASEB Journal, vol. 32, no. 3, pp. 11701183, 2018. 
[35] J. Ren and L. Zhang, "Effects of ovarian cancer G protein coupled receptor 1 on the proliferation, migration, and adhesion of human ovarian cancer cells," Chinese Medical Journal, vol. 124, no. 9, pp. 1327-1332, 2011.

[36] M. Raman, W. Chen, and M. H. Cobb, "Differential regulation and properties of MAPKs," Oncogene, vol. 26, no. 22, pp. 31003112, 2007.

[37] M. Kolev, L. Towner, and R. Donev, "Complement in cancer and cancer immunotherapy," Archivum Immunologiae et Therapia Experimentalis, vol. 59, no. 6, pp. 407-419, 2011.

[38] L. A. Trouw, M. C. Pickering, and A. M. Blom, "The complement system as a potential therapeutic target in rheumatic disease," Nature Reviews Rheumatology, vol. 13, no. 9, pp. 538547, 2017.

[39] M. J. Rutkowski, M. E. Sughrue, A. J. Kane, S. A. Mills, and A. T. Parsa, "Cancer and the complement cascade," Molecular Cancer Research, vol. 8, no. 11, pp. 1453-1465, 2010.

[40] Y. Yamada, M. Stoffel, R. Espinosa et al., "Human somatostatin receptor genes: localization to human chromosomes 14, 17, and 22 and identification of simple tandem repeat polymorphisms," Genomics, vol. 15, no. 2, pp. 449-452, 1993.

[41] S. M. Pasternack, I. Von Kügelgen, K. A. Aboud et al., "G protein-coupled receptor P2Y5 and its ligand LPA are involved in maintenance of human hair growth," Nature Genetics, vol. 40, no. 3, pp. 329-334, 2008.

[42] K. T. Weiss, M. Fante, G. Köhl et al., "Proton-sensing G proteincoupled receptors as regulators of cell proliferation and migration during tumor growth and wound healing," Experimental Dermatology, vol. 26, no. 2, pp. 127-132, 2017. 


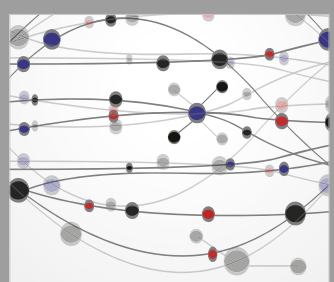

The Scientific World Journal
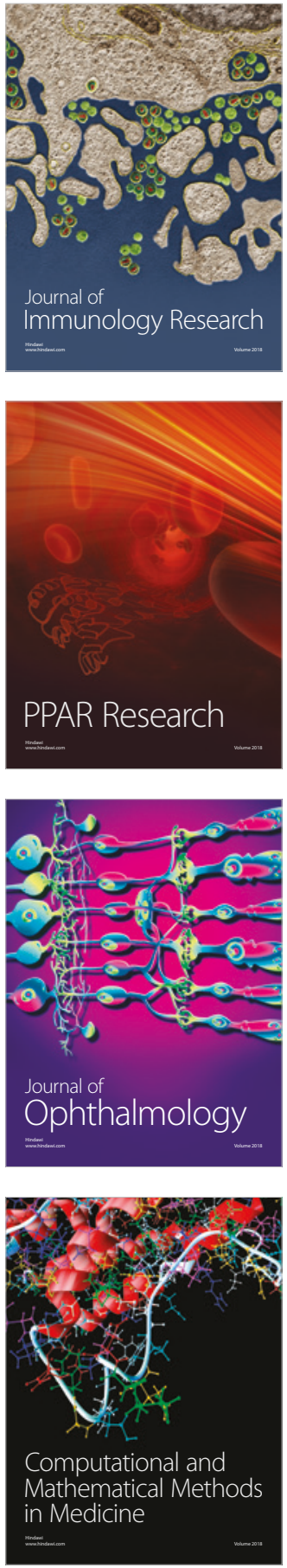

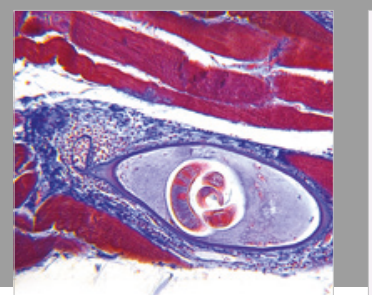

Gastroenterology Research and Practice

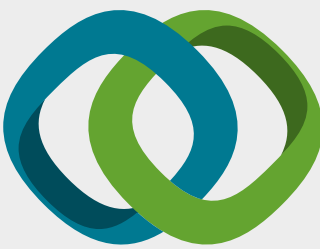

\section{Hindawi}

Submit your manuscripts at

www.hindawi.com
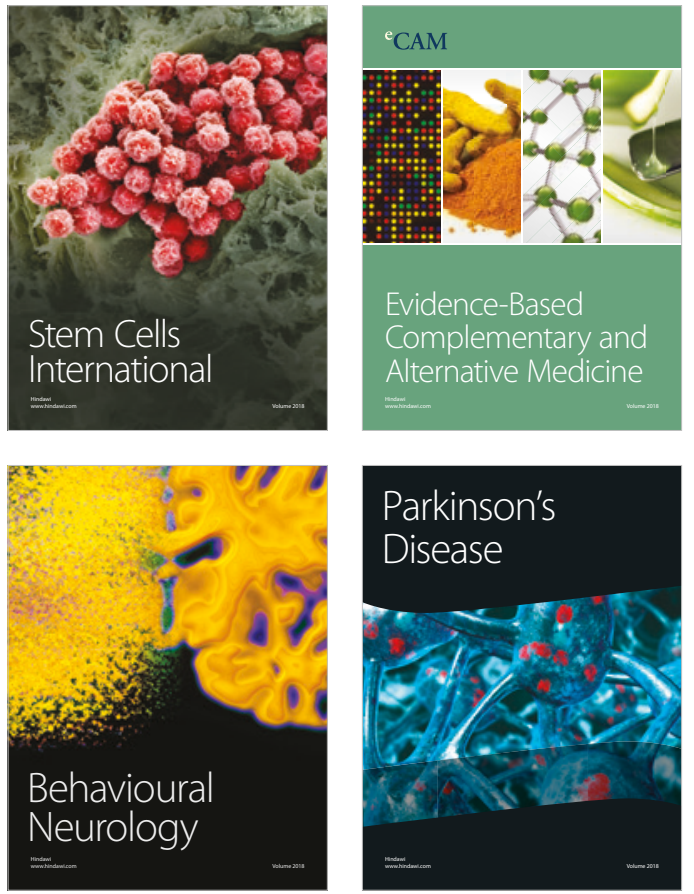

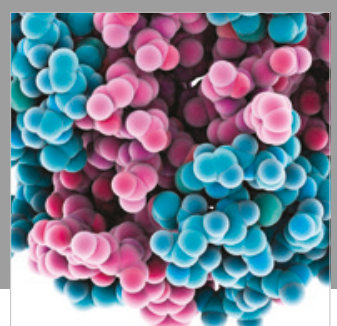

ournal of

Diabetes Research

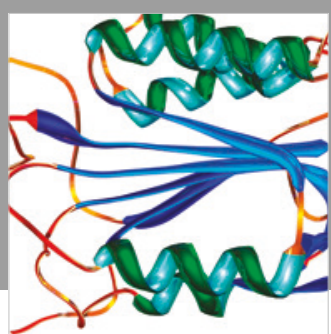

Disease Markers
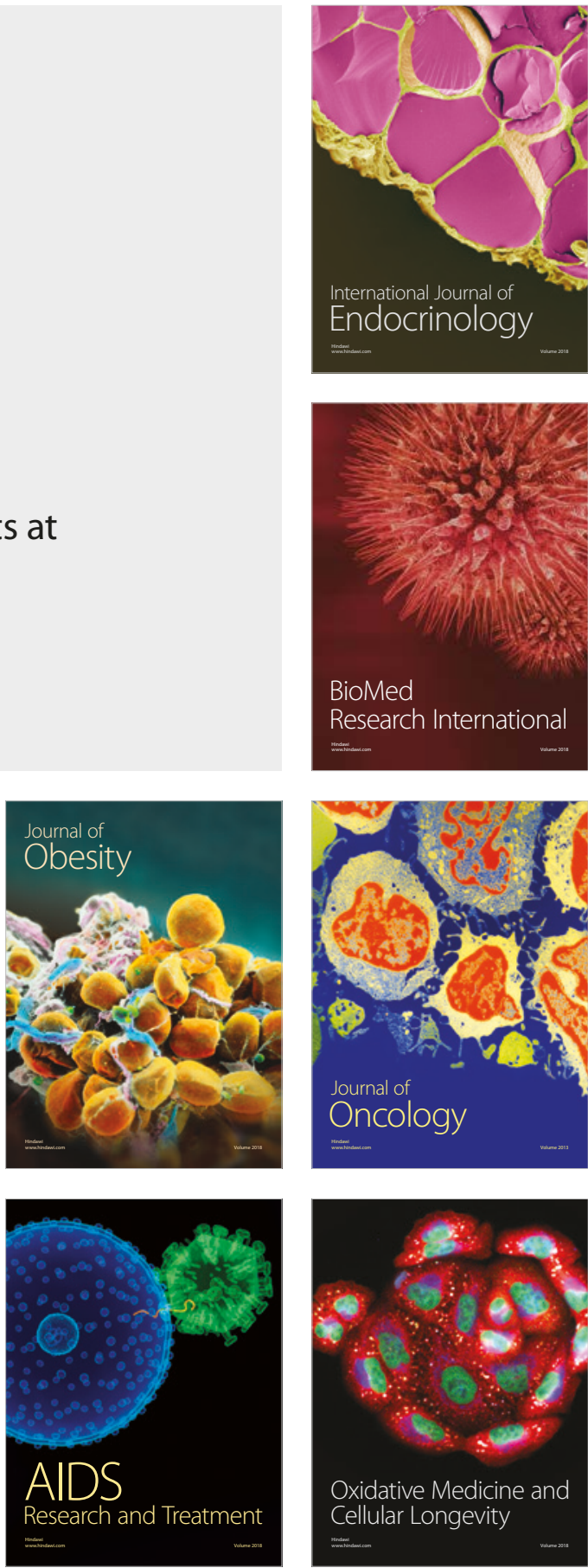